\title{
Magnetic Circuit Design and Magnetic Field Finite Element Analysis of Converging Stepped Magnetofluid Seal with Small Clearance
}

\author{
Xiaolong Yang $(\mathbb{D}$, Guohong Wang, and Ruibo Zhang \\ School of Mechanical Engineering, Guangxi University of Science and Technology, Liuzhou 545006, China \\ Correspondence should be addressed to Xiaolong Yang; 09116324@bjtu.edu.cn
}

Received 13 May 2020; Revised 1 June 2020; Accepted 16 June 2020; Published 17 July 2020

Academic Editor: Stefano Sorace

Copyright ( $) 2020$ Xiaolong Yang et al. This is an open access article distributed under the Creative Commons Attribution License, which permits unrestricted use, distribution, and reproduction in any medium, provided the original work is properly cited.

\begin{abstract}
The stepped magnetofluid seal is an effective method for improving the pressure ability of ordinary magnetofluid seals (OMS) with large clearance. At present, the research on stepped magnetofluid seal with less than $0.4 \mathrm{~mm}$ small clearance has not been carried out yet. The equivalent magnetic circuit design of converging stepped magnetofluid seal (CSMS) with small clearance has been carried out and verified by magnetic field finite element method based on the CSMS theory and magnetic circuit theory. The effects of the width of the axial seal position, the height of the radial seal position, the number of the pole tooth in the axial seal position, and the number of the pole tooth in the radial seal position on the theoretical pressure ability of the CSMS are investigated by numerical simulation. The calculation results are analyzed and discussed. The results show that the magnetic flux leakage at the junction of the permanent magnet and pole piece causes the higher pressure ability of the CSMS structure designed by the equivalent magnetic circuit method than that calculated by the magnetic field finite element method. When the width of the axial seal position is greater than the height of the radial seal position and the number of pole teeth in the axial seal position is less than the number of pole teeth in the radial seal position, the CSMS has the best effect. Compared with OMS with small clearance, CSMS has greater advantages.
\end{abstract}

\section{Introduction}

Magnetofluid is a kind of advanced intelligent material, which has become the research object of many researchers because of its stable and special properties [1]. Magnetofluid seals technique is a new kind of sealing method. In contrast to ordinary sealing, magnetofluid sealing has many strength points such as no wear, no leakage, no contamination, and lasting service life [2]. Therefore, magnetofluid seals are widely used in dynamic seals, isolation seal, and environmental seal [3-5].

At present, lots of research studies focus on OMS with less than $0.4 \mathrm{~mm}$ small clearance. Urreta and Mkubik et al. analyzed the sealing effect of two kinds of magnetofluid with different particle sizes to improve the pressure ability and to reduce friction torque and apply them to the spindle of high-precision machine tool [6, 7]. Zhang et al. studied and analyzed the influence of volume fraction of magnetofluid, magnetic field parameters, geometrical parameters, and different ester magnetofluids on the sealing ability of OMS [8]. Wang and Zhao et al. studied the mechanism of OMS and obtained the influence of temperature on the sealing performance of magnetofluid $[9,10]$. Szczech et al. carried out numerical simulation and experimental verification on the influence of magnetofluid volume, permanent magnet volume, polar tooth shape, and temperature on the sealing pressure performance $[11,12]$. But it is difficult for OMS to work in large clearance environment. Parmar designed static and dynamic seal tests with large radial clearance $(0.7 \mathrm{~mm})$ and verified its performance. Yang et al. proposed a new type of stepped magnetofluid seal used for large clearance condition [13]. The pressure capabilities of converging and diverging stepped magnetofluid seals were researched 
by numerical and experimental method, respectively, and were compared to that of the OMS. The results show that pressure ability of the stepped magnetofluid seal is better than that of the OMS [14, 15]. However, the existing stepped magnetofluid seals are aimed at the working environment of large clearance, and the study on CSMS under small clearance working condition has not been carried out yet.

This paper studied the CSMS with small clearance based on the CSMS with big clearance. The sealing structure of CSMS with small clearance and two magnetic sources is designed by the equality magnetic circuit way, and the pressure ability reliability of its structure designed by the equality magnetic circuit way is verified by the magnetic field finite element method. The effects of the axial seal position width, the radial seal position height, and the numbers of the pole teeth in the axial and radial seal position on the theoretical pressure capabilities of CSMS with small clearance have been investigated which can provide a theoretical basis for designing CSMS with small clearance and higher sealing performance.

\section{Materials and Methods}

Figure 1 is a schematic diagram of CSMS structure with small clearance and two magnetic origins. Its equivalent magnetic circuit is shown in Figure 2.

The magnetic field generated by the permanent magnet limits the magnetofluid to the seal position, and the magnetic field force acting on the magnetofluid is used to resist the pressure difference between two ends of the structure, so as to achieve the purpose of blocking the leakage channel.

As usual, the Bernoulli equation of magnetofluids can be shown (S. Parmar et al., 2018):

$$
P+\frac{1}{2} \rho_{f} V^{2}+\rho_{f} g h-\mu_{0} \int_{0}^{H} M \mathrm{~d} H=C,
$$

where $g$ is the gravitational acceleration; $h$ is the reference height; $V$ is the density; $M$ is the magnetization of magnetofluids; $P$ is the total pressure of magnetofluids; $\rho_{f}$ is the velocity; $\mu_{0}$ is the vacuum permeability; $H$ is the external magnetic field strength; and $C$ is the constant. In general, the composite pressure ability of magnetofluid static seal is easier to understand in the following equation [14]:

$$
\Delta P=\mu_{0} M_{s} \sum_{i=1}^{N}\left(H_{\max }^{i}-H_{\min }^{i}\right)=M_{s} \sum_{i=1}^{N}\left(B_{\max }^{i}-B_{\min }^{i}\right) .
$$

In (2), $M_{s}$ and $N$ are the saturation magnetization of the magnetofluid and the number of pole teeth; $H_{\min }^{i}, H_{\max }^{i}$, $B_{\min }^{i}$, and $B_{\max }^{i}$ are the minimum and maximum magnetic field strengths and the minimum and maximum magnetic inductions in the sealing position formed between the $i$ th pole tooth and the stepped shaft, respectively. follows:

$$
\Delta P_{c \max }=\sum_{i}^{N}\left(P_{i \mathrm{a}}+\lambda P_{i \mathrm{r}}\right),
$$

where $P_{i \mathrm{a}}$ and $P_{i \mathrm{r}}$ are the pressure abilities of the magnetofluid seal in the axial and in the radial seal positions formed by the stepped shaft and the $i$ th pole piece. If $P_{i_{\mathrm{a}}}$ is less than $P_{i \mathrm{r}}$, then $\lambda$ is 1 , otherwise 0 . The value of $P_{i \mathrm{a}}$ and $P_{i \mathrm{r}}$ can be calculated by equation (2).

The magnetic circuit devise of parallel CSMS includes two assumptions: first, ignoring magnetic leakage; second, ignoring edge effect. According to Kirchhoff's first law of magnetic circuit, it can be concluded that

$$
\sum \phi_{i}=0
$$

And it can be obtained that

$$
\phi_{2}=\phi_{1}+\phi_{3},
$$

where $\phi_{1}, \phi_{2}$, and $\phi_{3}$, respectively, are the magnetic flux passing through pole piece at high pressure side, middle pole pieces, and pole piece at the atmospheric side.

$$
\phi_{1}=3 B_{g 1}^{1} S_{g 1}^{1}+5 B_{g 2}^{1} S_{g 2}^{1},
$$

where $B_{g 1}^{1}$ and $B_{g 2}^{1}$, respectively, are the magnetic flux densities in the first axial seal position and radial seal position formed by stepped shaft and pole teeth of the first pile piece. $S_{g 1}^{1}$ and $S_{g 2}^{1}$ are, respectively, the magnetic flux densities in the first axial seal position and radial seal position formed by stepped shaft and pole teeth of the first pile piece.

$$
\phi_{2}=3 B_{g 1}^{4} S_{g 1}^{4}+5 B_{g 2}^{6} S_{g 2}^{6},
$$

where $B_{g 1}^{4}$ and $B_{g 2}^{6}$, respectively, are the magnetic flux densities in the first axial seal position and radial seal position formed by stepped shaft and pole teeth of the first pile piece. $S_{g 1}^{4}$ and $S_{g 2}^{6}$ are, respectively, the magnetic flux densities in the first axial seal position and radial seal position formed by stepped shaft and pole teeth of the first pile piece.

$$
\phi_{3}=3 B_{g 1}^{7} S_{g 1}^{7}+5 B_{g 2}^{11} S_{g 2}^{11},
$$

where $B_{g 1}^{7}$ and $B_{g 2}^{11}$, respectively, are the magnetic flux densities in the first axial seal position and radial seal position formed by stepped shaft and pole teeth of the first pile piece. $S_{g 1}^{7}$ and $S_{g 2}^{11}$ are, respectively, the magnetic flux densities in the first axial seal position and radial seal position formed by stepped shaft and pole teeth of the first pile piece.

$$
\phi_{\mathrm{m} 2}=B_{\mathrm{m} 2} S_{\mathrm{m} 2}=\phi_{3}=3 B_{g 1}^{7} S_{g 1}^{7}+5 B_{g 2}^{11} S_{g 2}^{11},
$$

where $\phi_{\mathrm{m} 2}, B_{\mathrm{m} 2}$, and $S_{\mathrm{m} 2}$, respectively, are the flux, flux density, and annular area of the second permanent magnet at the atmospheric side.

According to Kirchhoff's second law, the magnetic potential of the permanent magnet at the atmospheric pressure side can be expressed as follows: 


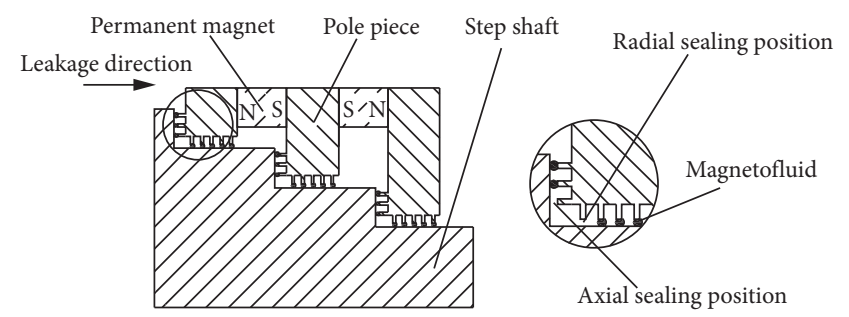

FIGURE 1: CSMS with small clearance. The enlarged area on the right side of the sketch shows the terms axial and radial seal positions used in the article.

$$
\begin{aligned}
F_{2}= & H_{\mathrm{m} 2} L_{\mathrm{m} 2}=\left(3 B_{g 1}^{4} S_{g 1}^{4}+5 B_{g 2}^{6} S_{g 2}^{6}\right) \\
& \cdot\left[R_{P 2}+\frac{\left(R_{t 1}^{4}+R_{g 1}^{4}\right)\left(R_{t 2}^{6}+R_{g 2}^{6}\right)}{3\left(R_{t 2}^{6}+R_{g 2}^{6}\right)+5\left(R_{t 1}^{4}+R_{g 1}^{4}\right)}\right] \\
& +\left(3 B_{g 1}^{7} S_{g 1}^{7}+5 B_{g 2}^{11} S_{g 2}^{11}\right) \\
& \cdot\left[R_{P 3}+R_{a 2}+R_{\mathrm{m} 2}+\frac{\left(R_{t 1}^{7}+R_{g 1}^{7}\right)\left(R_{t 2}^{11}+R_{g 2}^{11}\right)}{3\left(R_{t 2}^{11}+R_{g 2}^{11}\right)+5\left(R_{t 1}^{7}+R_{g 1}^{7}\right)}\right],
\end{aligned}
$$

where $H_{\mathrm{m} 2}$ and $L_{\mathrm{m} 2}$, respectively, are the magnetic field strength and the length of the second permanent magnet. $R_{p 3}$, $R_{a 2}$, and $R_{\mathrm{m} 2}$, respectively, are the magnetic resistances of the third pole piece, the second step, and the second permanent magnet. $R_{t 1}^{4}$ and $R_{g 1}^{4}$, respectively, are the reluctance of the fourth polar tooth in the axial seal position and the fourth seal position in the axial seal position. $R_{t 2}^{6}$ and $R_{g 2}^{6}$, respectively, are the reluctance of the sixth polar tooth in the axial seal position and the sixth seal position.

When (9) is multiplied by (10), the volume of permanent magnet can be calculated as follows:

$$
V_{\mathrm{m} 2}=S_{\mathrm{m} 2} L_{\mathrm{m} 2}=\frac{F_{2} \phi_{\mathrm{m} 2}}{B_{\mathrm{m} 2} H_{\mathrm{m} 2}} \text {. }
$$

In order to increase the utilization rate of permanent magnet, permanent magnet should work at their maximum magnetic energy product:

$$
V_{\mathrm{m} 2}=S_{\mathrm{m} 2} L_{\mathrm{m} 2}=\frac{F_{2} \phi_{\mathrm{m} 2}}{(B H)_{\max }} .
$$

When (9) is divided by (10), the following formula can be obtained:

$$
\frac{S_{\mathrm{m} 2}}{L_{\mathrm{m} 2}}=\frac{\left(3 B_{g 1}^{7} S_{g 1}^{7}+5 B_{g 2}^{11} s_{g 2}^{11}\right) H_{\mathrm{m} 2}}{F_{2} B_{\mathrm{m} 2}} .
$$

When (12) is multiplied by (13), the cross-sectional area of the permanent magnet can be calculated as follows:

$$
S_{\mathrm{m} 2}=\left(3 B_{g 1}^{7} S_{g 1}^{7}+5 B_{g 2}^{11} s_{g 2}^{11}\right) \sqrt{\frac{H_{\mathrm{m} 2}}{(B H)_{\max } B_{\mathrm{m} 2}}} .
$$

When (12) is divided by (13), the length of the permanent magnet can be calculated as follows:

$$
L_{\mathrm{m} 2}=F_{2} \sqrt{\frac{B_{\mathrm{m} 2}}{(B H)_{\max } H_{\mathrm{m} 2}}} .
$$

Because the magnetic permeability of pole pieces and shaft is much greater than that of air and permanent magnet, the magnetic resistance of pole piece and shaft can be neglected in calculating the length of permanent magnet. The length of the permanent magnet can be calculated by the following expression:

$$
\begin{aligned}
L_{\mathrm{m} 2}= & \left\{\left(3 B_{g 1}^{4} S_{g 1}^{4}+5 B_{g 2}^{6} S_{g 2}^{6}\right)\left[\frac{R_{g 1}^{4} R_{g 2}^{6}}{3 R_{g 2}^{6}+5 R_{g 1}^{4}}\right]+\left(3 B_{g 1}^{7} S_{g 1}^{7}+5 B_{g 2}^{11} S_{g 2}^{11}\right)\right. \\
& \left.\cdot\left[R_{\mathrm{m} 2}+\frac{R_{g 1}^{7} R_{g 2}^{11}}{3 R_{g 2}^{11}+5 R_{g 1}^{7}}\right]\right\} \sqrt{\frac{H_{\mathrm{m} 2}}{(B H)_{\max } B_{\mathrm{m} 2}}}
\end{aligned}
$$

According to the known demagnetizing curve and magnetic circuit parameters of permanent magnet, the length and cross-sectional area of permanent magnet can be calculated, so as to ensure the maximum magnetic energy product in the sealing position and improve the utilization rate of permanent magnet.

If the sealing pressure resistance is required to be not less than $7.5 \times 10^{5} \mathrm{~Pa}$, the total magnetic induction intensity difference is $16.6 \mathrm{~T}$ according to the theory of polymerized magnetic fluid seal. According to Table 1 and (13) and (15), the length and cross section of the permanent magnet can be calculated. The length is $4 \mathrm{~mm}$, and the cross section of the permanent magnet $703.716 \mathrm{~mm}^{2}$. The structure parameters of CSMS designed by magnetic circuit theory are shown in Table 1.

To verify the reliability of CSMS with small clearance devised by magnetic circuit theory and research, the effects of the radial and axial seal positions and pole teeth numbers on its pressure capabilities, the magnetic field finite element method has been employed. Because of the symmetry of the seal structure, the three-dimensional axisymmetric problem of the CSMS is simplified to be a two-dimensional plane model. In numerical simulation method, the program ANSYS 15 was used. In the numerical simulations, an axially symmetric model was adopted, as was the Dirichlet boundary condition. The physical environment of the magnetofluid seal is created in the preprocessor of ANSYS finite element analysis software. And because the magnetic field strength in the sealing position produced by the permanent magnet is much more than that required by the saturated magnetized magnetofluid, magnetization of the magnetofluid will reach its maximum value. The magnetic permeability difference between the saturated magnetized magnetofluid and the air is very small, so the magnetofluid can be treated as air approximately. The coercivity of $\mathrm{Nd}-\mathrm{Fe}$ $\mathrm{B}$ permanent magnet is $1.356 * 106 \mathrm{~A} / \mathrm{m}$. The magnetofluid is an oil-based fluid and the saturation magnetization is $30.7 \mathrm{kA} / \mathrm{m}$. The corresponding material attributes are given to each component. The magnetic field computation was performed by use of intelligent mesh with precision 1 . The Dirichlet boundary condition is applied, and the magnetic 


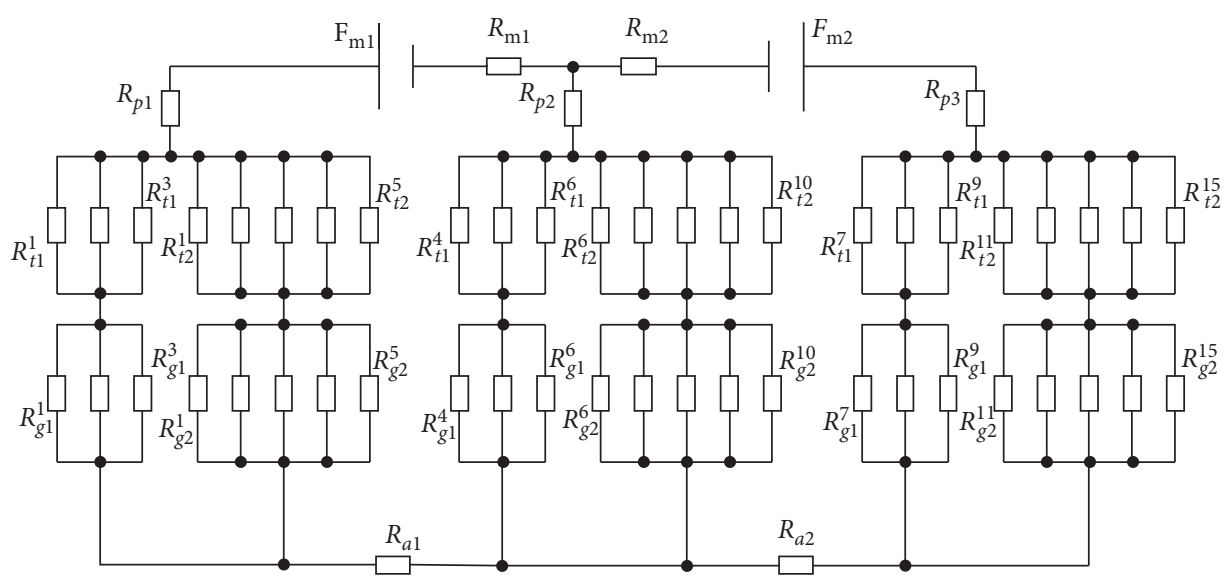

Figure 2: The equivalent magnetic circuit.

TABLE 1: The parameters of converging stepped magnetofluid seal with small clearance.

\begin{tabular}{lc}
\hline Item & Value \\
\hline Inner radius of the $1 / 2 / 3$ pole piece $(\mathrm{mm})$ & $21 / 17 / 13$ \\
Outer radius of the $1 / 2 / 3$ pole piece $(\mathrm{mm})$ & 30 \\
Length of the $1 / 2 / 3$ pole piece $(\mathrm{mm})$ & 5.3 \\
Pole tooth number of the $1 / 2 / 3$ pole piece in the axial seal position & 3 \\
Pole tooth number of the $1 / 2 / 3$ pole piece in the radial seal position & 5 \\
Axial seal position width $(\mathrm{mm})$ & 0.1 \\
Radial seal position width $(\mathrm{mm})$ & 0.1 \\
Width of pole tooth $(\mathrm{mm})$ & 0.3 \\
Slot depth $(\mathrm{mm})$ & 0.8 \\
Slot width $(\mathrm{mm})$ & 0.7 \\
\hline
\end{tabular}

flux density distributions in the radial and axial seal positions could be gained by the ANSYS solver.

\section{Results and Discussion}

3.1. Reliability of CSMS Designed by Magnetic Circuit Method. Through the above numerical analysis, magnetic flux density distribution in the sealing position of CSMS is shown in Figure 3 and the distribution of the magnetic force line is shown in Figure 4.

It can be seen from Figure 3 that the maximum magnetic flux density passing through the pole teeth of the middle pole piece is obviously greater than that passing through the pole teeth of the other two pole pieces because of the magnetic field strength in the middle pole piece generated by two magnetic sources.

According to (2) and (3) and magnetic flux density distribution as shown in Figure 3, the theoretical pressure ability of the CSMS should be $6.9 * 105 \mathrm{~Pa}$ which is smaller than the required value of the magnetic circuit design and the error is $8 \%$. This proves the reliability of CSMS designed by the magnetic circuit. The main reason of error is that the magnetic flux leakages occur at the junctions of permanent magnets and pole piece as shown in Figure 4.

\subsection{Effect of Sealing Position Height and Width on CSMS.} When the size of the axial seal position is $0.1 \mathrm{~mm}$, the magnetic field distribution in the small sealing position of
CSMS with different radial seal position heights is shown in Figure 5 .

It can be seen from Figure 5 that the magnetic flux density in the axial seal position enlarges slowly and the magnetic flux density in the radial seal position reduces with the increase of the radial seal position height. The reason for this change is that the increase of the radial seal position height will enlarge the magnetic resistance of the radial seal position which causes the increase of the magnetic resistance of the whole magnetic circuit and the decrease of the magnetic flux of the whole magnetic circuit. According to the magnetic circuit theory, the increase of the magnetic potential of the radial seal position is far less than the increase of its magnetic resistance. Hence, magnetic flux density in the radial seal position reduces as the radial seal position height enlarges. On the other hand, the magnetic resistance of the axial seal position remains unchanged when the axial seal position width remains unchanged. The magnetic potential of the axial seal position enlarges with the increasing height of the radial seal position. Therefore, the magnetic flux density in the axial seal position enlarges slowly with the increasing height of the radial seal position.

When the size of the radial seal position is $0.1 \mathrm{~mm}$, the magnetic field distribution in the small sealing position of CSMS with different axial seal position weight is shown in Figure 6.

It can be seen from Figure 6 that the magnetic flux density in the radial seal position enlarges slowly and the 


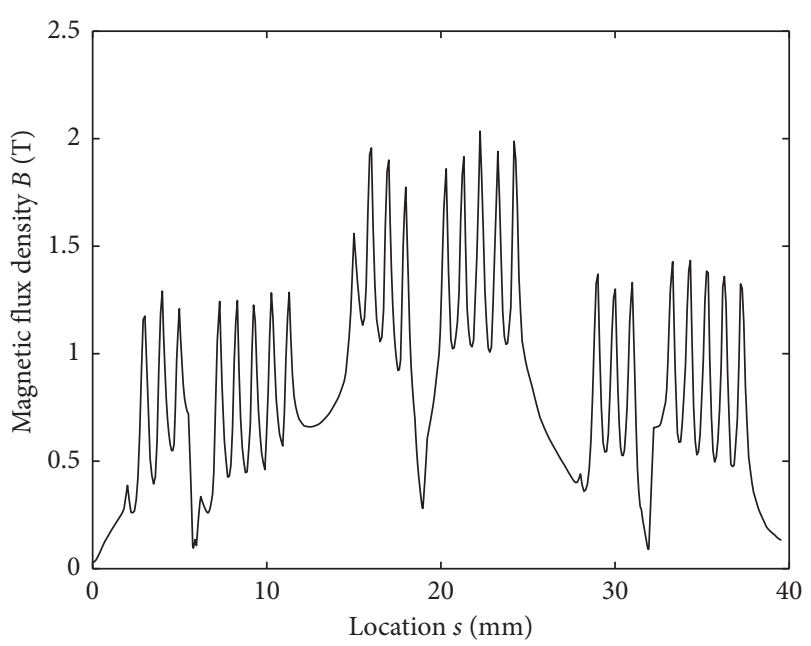

Figure 3: Magnetic field distribution.

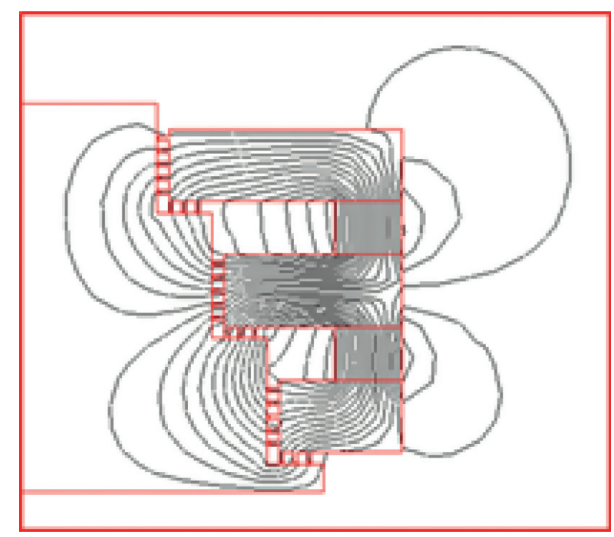

Figure 4: Distribution of the magnetic force line.

magnetic flux density in the axial seal position reduces with the increase of the axial seal position height. The reason for this change is that the increase of the axial seal position height will increase the magnetic resistance of the axial seal position which causes the increase of the magnetic resistance of the whole magnetic circuit and the decrease of the magnetic flux of the whole magnetic circuit. According to the magnetic circuit theory, the increase of the magnetic potential of the axial seal position is far less than the increase of its magnetic resistance. Hence, the magnetic flux density in the axial seal position reduces as the axial seal position height enlarges. On the other hand, magnetic resistance of the radial seal position remains unchanged when the radial seal position width remains unchanged. The magnetic potential of the radial seal position enlarges with the increasing height of the axial seal position. Therefore, the magnetic flux density in the radial seal position enlarges slowly with the increasing height of the axial seal position.

According to (2) and (3) and the magnetic field distributions as shown in Figures 5 and 6, the effects of the radial and axial seal positions on the pressure capabilities of CSMS and the comparison of the pressure capabilities between the CSMS and the OMS under different seal positions can be obtained as shown in Figures 7 and 8.

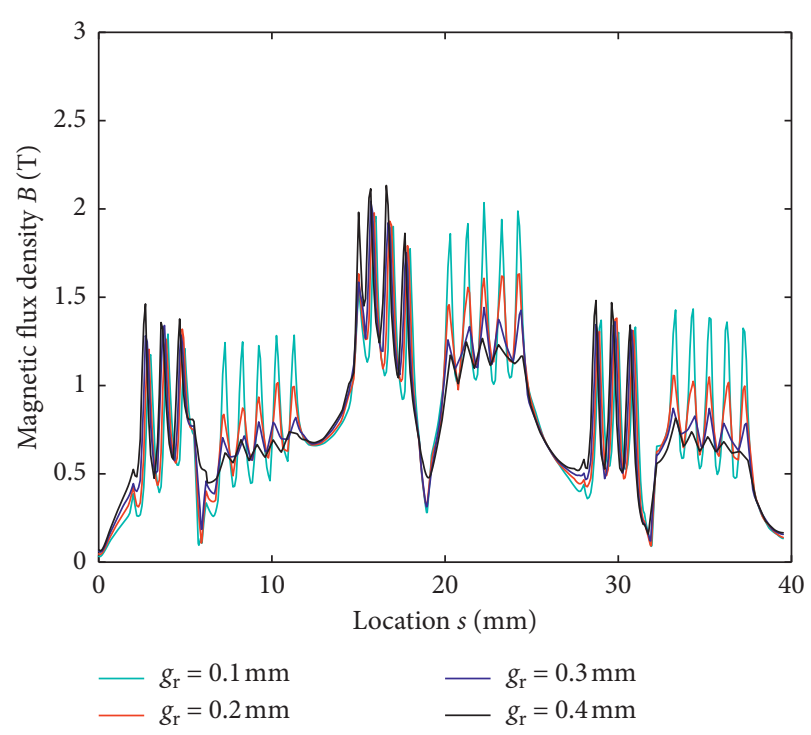

Figure 5: Magnetic field distribution with different radial sealing position heights. $g_{\mathrm{r}}$ : radial sealing position height.

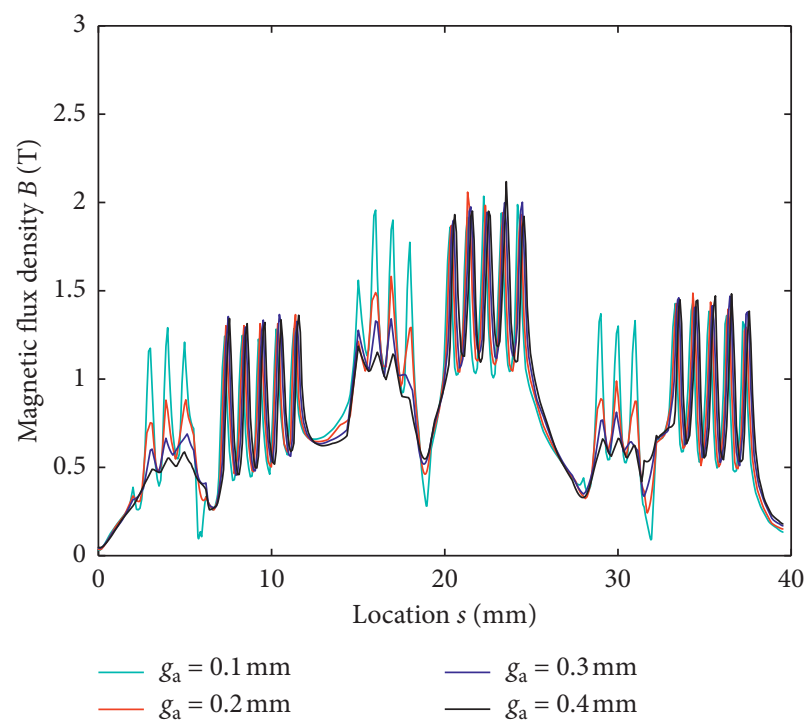

Figure 6: Magnetic field distribution with different axial sealing position widths. $g_{\mathrm{a}}$ : axial sealing position width.

From Figure 7, it can be seen that when the radial seal position height is $0.1 \mathrm{~mm}$ and the axial seal position width is greater than or equal to the radial seal position height, the theoretical pressure ability of the CSMS reduces with the increasing width of the axial seal position. The reason is that when the pressure ability of CSMS in the axial seal position is less than that in the radial seal position, the theoretical pressure ability of the seal structure is the sum of the pressure ability of the CSMS in the axial and the radial seal positions according to the theory of seal structure. Although the magnetic flux density in the axial seal position reduces with the increase of the height of the axial seal position and the magnetic flux density in the radial seal position enlarges slowly with the increase of the height of the axial seal 


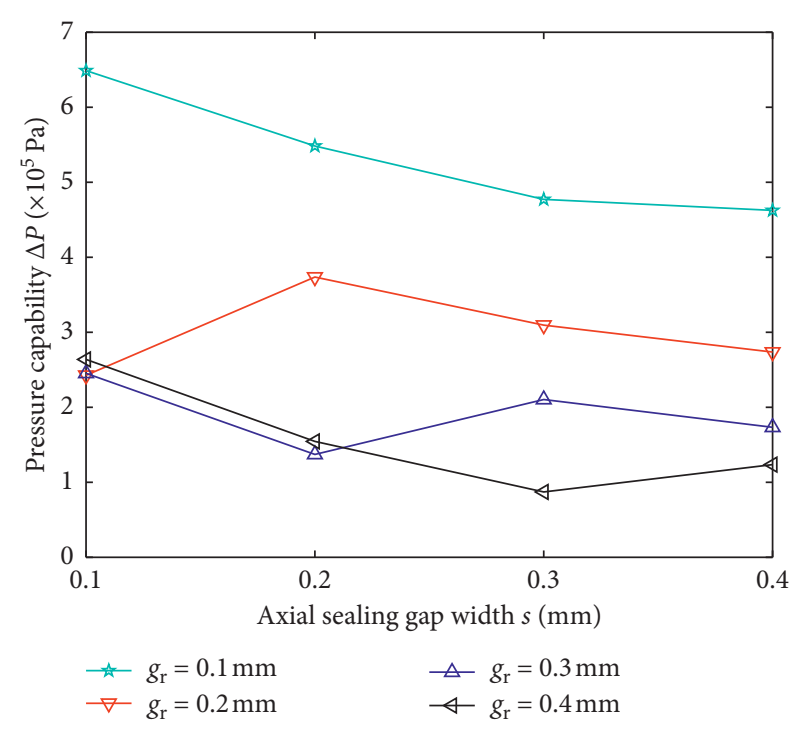

FIGURE 7: Effect of sealing positions on sealing capability. $g_{\mathrm{r}}$ : radial sealing position height.

position as shown in Figure 6, the decrement of magnetic flux density in the axial seal position is much larger than the increment of magnetic flux density in radial seal position. So, the theoretical pressure ability of CSMS reduces with the increasing width of axial seal position.

When the radial seal position height is $0.2 \mathrm{~mm}$ which is within the range of the axial seal position width, the theoretical pressure ability of the CSMS enlarges firstly and then reduces with the increase of the axial seal position width. This is because when the axial seal position width is less than the radial seal position height, the pressure ability of the CSMS in the axial seal position is greater than that in the radial seal position. According to the theory of the CSMS, the theoretical pressure ability of the CSMS depends only on the pressure ability of CSMS in the axial seal position. It means that the CSMS in the radial seal position does not work. When the axial seal position is greater than or equal to the radial seal position, the pressure ability of CSMS in the axial seal position is less than that in the radial seal position; the theoretical pressure ability of the CSMS is the sum of the pressure ability of the CSMS in the axial and the radial seal positions according to the theory of CSMS. And the reduction of magnetic flux density in the axial seal position is much less than that in the radial seal position when the axial seal position equals the radial seal position as shown in Figure 6. Therefore, the theoretical pressure ability of the CSMS enlarges firstly as the axial seal position enlarges. And the decrement of magnetic flux density in the axial seal position is much larger than the increment of magnetic flux density in radial seal position when the axial seal position width is larger than the radial seal position height. So, the theoretical pressure ability of CSMS reduces with the increasing width of axial seal position.

When the radial seal position is $0.3 \mathrm{~mm}$, which is within the range of the axial seal position, the theoretical pressure ability of the CSMS structure initially reduces with the increasing axial seal position width, followed by an increase

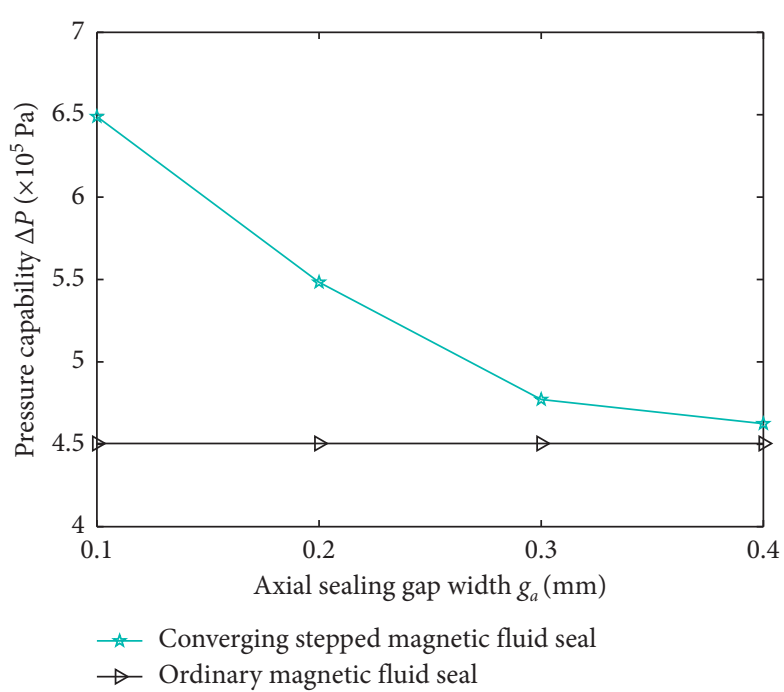

Figure 8: Pressure capability comparison between converging stepped seal and ordinary seal.

upon which it begins to decrease once again. This is because when the axial seal position width is less than the radial seal position height, the pressure ability of the CSMS in the axial seal position is greater than that in the radial seal position. According to the theory of the CSMS, the theoretical pressure ability of the CSMS depends only on the pressure ability of CSMS in the axial seal position. It means that the CSMS in the radial seal position does not work. And it can be seen from Figure 6 that the magnetic flux density in the axial seal position reduces with the increase of the height of the axial seal position, so the theoretical pressure ability of the CSMS reduces first with the increase of the axial seal position width. When the pressure ability of CSMS in the axial seal position is less than that in the radial seal position with increasing width of axial seal position, the theoretical pressure ability of the CSMS is the sum of the pressure ability of the CSMS in the axial and the radial seal positions according to the theory of CSMS. And the reduction of magnetic flux density in the axial seal position is much less than that in the radial seal position when the axial seal position equals the radial seal position as shown in Figure 6. Therefore, the theoretical pressure ability of the CSMS enlarge secondly as the axial seal position enlarge. Although the magnetic flux density in the axial seal position reduces with the increase of the height of the axial seal position and the magnetic flux density in the radial seal position enlarges slowly with the increase of the height of the axial seal position as shown in Figure 6, the decrement of magnetic flux density in the axial seal position is much larger than the increment of magnetic flux density in radial seal position. So, the theoretical pressure ability of CSMS reduces lastly with the increasing width of axial seal position.

From Figure 7, it can be seen that when the radial seal position height is $0.4 \mathrm{~mm}$ and the axial seal position width is less than or equal to the radial seal position height, the theoretical pressure ability of the CSMS reduces firstly and increases lastly with the increasing width of the axial seal position. The reason is that when the axial seal position 
width is less than the radial seal position height, the pressure ability of the CSMS in the axial seal position is greater than that in the radial seal position. According to the theory of the CSMS, the theoretical pressure ability of the CSMS depends only on the pressure ability of CSMS in the axial seal position. And it can be seen from Figure 6 that the magnetic flux density in the axial seal position reduces with the increase of the height of the axial seal position, so the theoretical pressure ability of the CSMS is decreasing firstly with the increasing width of axial seal position. The theoretical pressure ability of the CSMS is the sum of the pressure ability of the CSMS in the axial and the radial seal positions according to the theory of CSMS when the axial seal position width and radial seal position height are equal. Therefore, the theoretical pressure ability of the CSMS enlarges lastly with the increasing width of axial seal position.

Figure 8 shows that when the radial seal position is $0.1 \mathrm{~mm}$ and the axial seal position is greater than or equal to the radial seal position, the pressure ability of the CSMS is much greater than that of the OMS. The smaller the axial seal position is, the larger the pressure ability difference between them is. When the axial seal position is $0.1 \mathrm{~mm}$, the pressure ability of CSMS is about 1.5 times that of OMS. The reason is that when the radial seal position is $0.1 \mathrm{~mm}$ and the axial seal position is greater than or equal to the radial seal position, the pressure ability of CSMS in the axial seal position is less than that in the radial seal position; the theoretical pressure ability of the CSMS is the sum of the pressure ability of the CSMS in the axial and the radial seal positions according to the theory of CSMS. However, only the CSMS in the radial seal position plays a role for ordinary pressure seal, so the pressure ability of the CSMS is much greater than that of the OMS.

3.3. Effect of Pole Tooth Number on CSMS. When the number of pole teeth in the axial seal position is 1 , the magnetic field distribution in the small-sealing seal position of CSMS with different number of pole teeth in the radial seal position is shown in Figure 9.

It can be seen from Figure 9 that the magnetic flux density in the radial and axial seal positions reduces with the increasing width of the pole tooth number in the radial seal position. The reason for this change is that the increase of the number of pole teeth in the radial seal position will decrease the total magnetic resistance of the pole tooth in the radial seal position which causes the decrease of the total magnetic resistance of the magnetic circuit and the decrease of the magnetic potential. According to the magnetic circuit theory, magnetic flux density of the axial seal position reduces as the number of pole teeth in the radial seal position enlarges. On the other hand, when the magnetic resistance in the radial seal position reduces and the magnetic resistance in the axial seal position remains unchanged, the total magnetic flux of the pole tooth magnetic resistance through the radial seal position enlarges relatively, but because the number of pole teeth in the radial seal position enlarges, the total magnetic flux enlarges much faster than that in the pole tooth in the radial seal position. Hence, the magnetic flux density in the pole tooth of the radial seal position reduces.

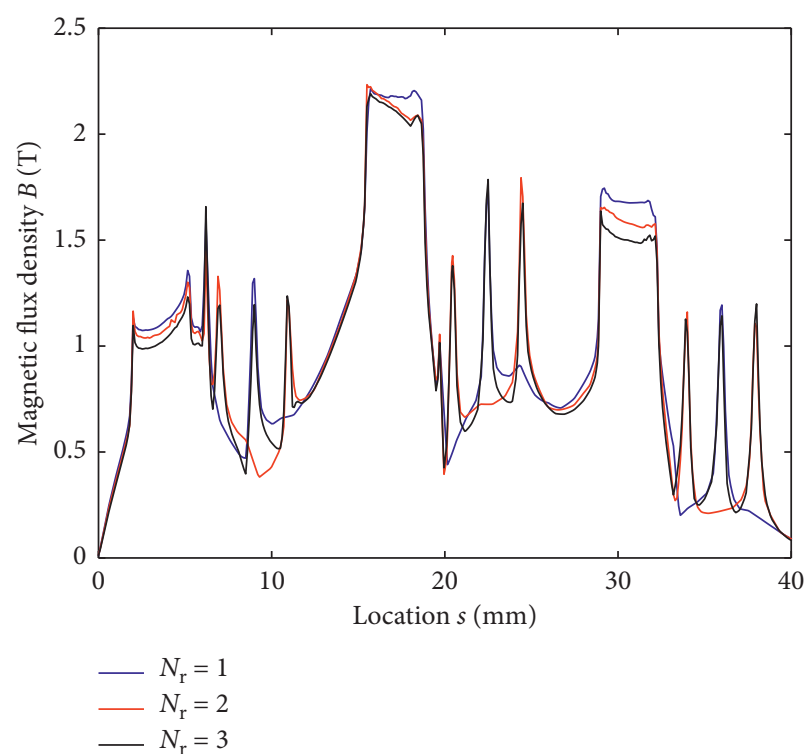

FIgURE 9: Magnetic field distribution with different teeth number in the radial sealing position. $N_{\mathrm{r}}$ : radial teeth.

When the number of pole teeth in the radial seal position is 3 , the magnetic field distribution in the small sealing seal position of CSMS with different number of pole teeth in the axial seal position is shown in Figure 10.

It can be seen from Figure 10 that the magnetic flux density in the radial and axial seal positions reduces with the increasing width of the pole tooth number in the radial seal position. The reason for this change is that the increase of the number of pole teeth in the axial seal position will decrease the total magnetic resistance of the pole tooth in the axial seal position which causes the decrease of the total magnetic resistance of the magnetic circuit and the decrease of the magnetic potential. According to the magnetic circuit theory, magnetic flux density of the radial seal position reduces as the number of pole teeth in the axial seal position enlarges. On the other hand, when the magnetic resistance in the axial seal position reduces and the magnetic resistance in the radial seal position remains unchanged, the total magnetic flux of the pole tooth magnetic resistance through the axial seal position enlarges relatively, but because the number of pole teeth in the axial seal position enlarges, the total magnetic flux enlarges much faster than that in the pole tooth in the axial seal position. Hence, the magnetic flux density in the pole tooth of the axial seal position reduces.

According to (2) and (3) and magnetic field distributions as shown in Figures 9 and 10, the effects of the pole tooth number on CSMS radial and axial seal positions on the pressure capabilities of CSMS and the comparison of the pressure capabilities between the CSMS and the OMS under different pole tooth number can be obtained as shown in Figure 11 and 12 .

From Figure 11, it can be seen that when the number of pole teeth in the axial seal position is 1, the theoretical pressure ability of the CSMS enlarges with the increasing number of pole teeth in the radial seal position. The reason is that when the number of pole teeth in the axial seal position 


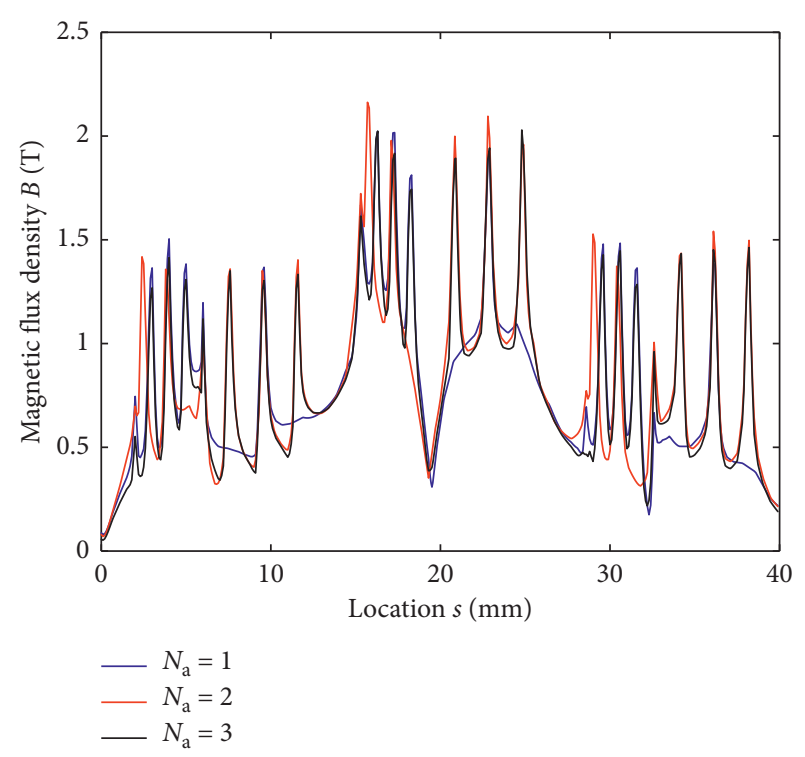

Figure 10: Magnetic field distribution with different teeth number in the axial sealing position. $N_{\mathrm{a}}$ : axial teeth number.

is less than or equal to the number of pole teeth in the radial seal position, the pressure ability of CSMS in the axial seal position is less than that in the radial seal position, the theoretical pressure ability of the CSMS is the sum of the pressure ability of the CSMS in the axial and the radial seal positions according to the theory of CSMS. And the increase of total difference of magnetic flux density is much larger than the decrease of magnetic flux density with the increase of the number of pole teeth in radial seal position as shown in Figure 9, so the theoretical pressure ability of CSMS enlarges with the increase of the number of pole teeth in radial seal position.

When the number of pole teeth in the axial seal position is 2, the theoretical pressure ability of the CSMS enlarges with the increase of the number of pole teeth in the radial seal position. This is because when the number of pole teeth in the axial seal position is larger than the number of pole teeth in the radial seal position, the pressure ability of the CSMS in the axial seal position is greater than that in the radial seal position. According to the theory of the CSMS, the theoretical pressure resistance of the CSMS depends only on the CSMS pressure resistance ability in the axial seal position. It means that the CSMS in the radial seal position does not work. When the number of pole teeth in the axial seal position is less than or equal to the number of pole teeth in the radial seal position, the pressure ability of CSMS in the axial seal position is less than that in the radial seal position; the theoretical pressure ability of the CSMS is the sum of the pressure ability of the CSMS in the axial and the radial seal positions according to the theory of CSMS. And the increase of total difference of magnetic flux density is much larger than the decrease of magnetic flux density with the increase of the number of pole teeth in radial seal position as shown in Figure 9, so the theoretical pressure ability of CSMS enlarges with the increase of the number of pole teeth in radial seal position.

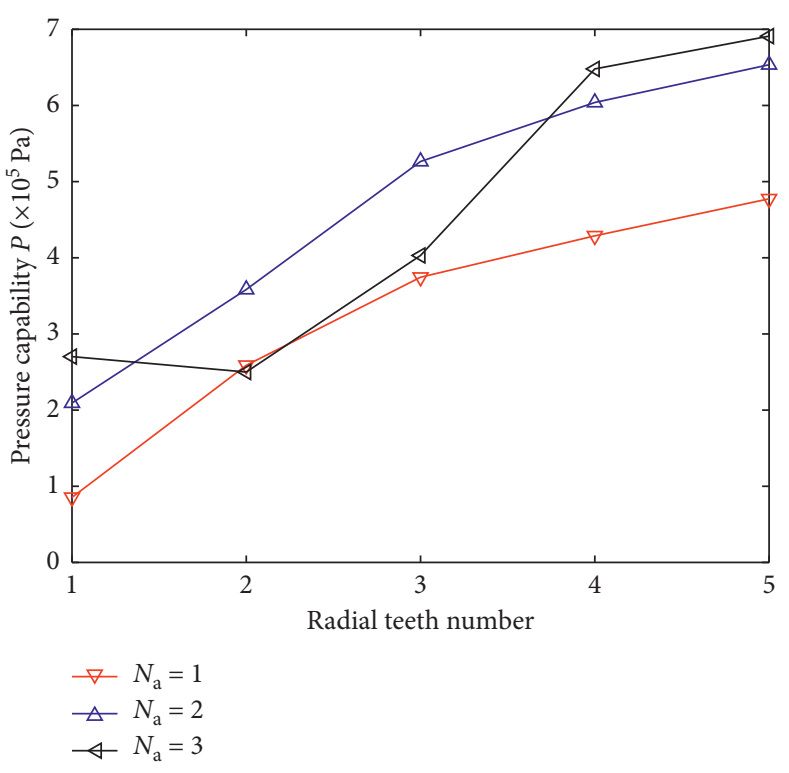

FIgURE 11: Effect of teeth number on sealing capability. $N_{\mathrm{a}}$ : axial teeth number.

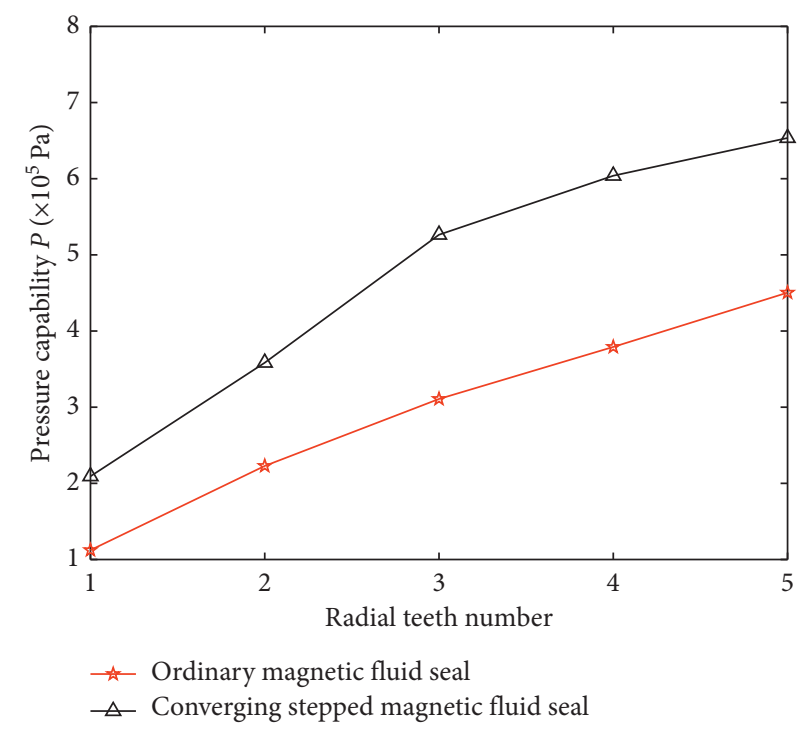

FIGURE 12: Pressure capability comparison between CSMS and OMS.

When the number of pole teeth in the axial seal position is 3 , the theoretical pressure ability of the seal structure reduces first and then enlarges with the increase of the number of pole teeth in the radial seal position. This is because when the number of pole teeth in the axial seal position is larger than the number of pole teeth in the radial seal position, the pressure ability of the CSMS in the axial seal position is greater than that in the radial seal position. According to the theory of the CSMS, the theoretical pressure resistance of the seal structure depends only on the CSMS pressure resistance ability in the axial seal position. It means that the CSMS in the radial seal position does not work. So the theoretical pressure ability of the CSMS reduces 
with the increase of the number of pole teeth in the radial seal position. When the number of pole teeth in the axial seal position is less than or equal to the number of pole teeth in the radial seal position, the pressure ability of CSMS in the axial seal position is less than that in the radial seal position; the theoretical pressure ability of the CSMS is the sum of the pressure ability of the CSMS in the axial and the radial seal positions according to the theory of CSMS. And the increase of total difference of magnetic flux density is much larger than the decrease of magnetic flux density with the increase of the number of pole teeth in radial seal position as shown in Figure 9, so the theoretical pressure ability of CSMS enlarges with the increase of the number of pole teeth in radial seal position.

Figure 12 shows that when the number of internal pole teeth in the axial seal position is 2, the pressure ability of the CSMS is much greater than that of the OMS. When the number of pole teeth in the radial seal position is 3 , the pressure resistance of the CSMS is about 1.6 times that of the OMS. The reason is that when the number of pole teeth in the axial seal position is less than or equal to the number of pole teeth in the radial seal position, the pressure ability of CSMS in the axial seal position is less than that in the radial seal position; the theoretical pressure ability of the CSMS is the sum of the pressure ability of the CSMS in the axial and the radial seal positions according to the theory of CSMS. However, only the CSMS in the radial seal position plays a role for OMS, so the pressure ability of the CSMS is much greater than that of the OMS.

\section{Conclusions}

By comparing the results of finite element analysis and magnetic circuit design, the reliability of magnetic circuit design is verified. At the same time, the result of magnetic circuit design is slightly larger than that of finite element analysis. The main reason is the existence of magnetic leakage. In order to improve the accuracy of magnetic circuit design, materials with high magnetic resistance can be selected in areas where the magnetic circuit does not pass through. The pressure ability of CSMS with small clearance depends not only on the number of pole teeth in the axial seal position and the axial seal position, but also on the number of pole teeth in the radial seal position and the radial seal position. When the number of pole teeth in the axial seal position is less than or equal to the number of pole teeth in the radial seal position, the pressure ability effect of the CSMS is better than that of the situation in which the number of pole teeth in the axial seal position is smaller than the number of pole teeth in the radial seal position. When the axial seal position is bigger than or equal to the radial seal position, the pressure ability effect of the CSMS is better than that of the opposite situation. Compared with OMS with small clearance, CSMS has greater advantages.

\section{Data Availability}

The data in the supplementary file is the text file obtained from the analysis of ANSYS 15. The magnetization curve of the magnet is measured by the magnetometer. The model in the paper is imported into ANSYS, the material parameters are input, the grid is divided, and a path is defined after solving. The magnetic induction intensity can be mapped to the curve. And output data in text format ga, gr, nr, and na in the file name, respectively, represent the axial sealing position width, the radial sealing position height, the radial teeth number, and the axial teeth number. The first column s is the leakage path length, and the second column $\mathrm{A}$ is the magnetic induction intensity at the current point corresponding to $s$. The following are the steps of data processing. The first step is to find out the peaks and troughs of the curve and calculate the difference between each peak and troughs. In the second step, according to the model and the formula in this paper, the corresponding difference is calculated to get the total magnetic induction strength difference of the seal. The third step is to multiply the total magnetic induction difference and the saturation magnetization of the magnetic fluid to obtain the total pressure resistance of the seal.

\section{Conflicts of Interest}

The authors declare that they have no conflicts of interest regarding the publication of this paper.

\section{Acknowledgments}

The authors gratefully acknowledge the support of the National Natural Science Foundation of China (Grant no. 51905114), the support of the Science and Technology Project of Guangxi Province (Grant no. 2016GXNSFBA380213), the support of the Innovation Project of Guangxi University of Science and Technology Graduate Education (Grant no. GKYC201901), and the support of the Science and Technology Project of Liuzhou (Grant no. 2017BC20204).

\section{Supplementary Materials}

The data in the supplementary file are the text files obtained from the analysis of ANSYS. The magnetization curve of the magnet is measured by the magnetometer. The model in the paper is imported into ANSYS. The material parameters are input, the grid which is divided, and a path which is defined after solving. The magnetic induction intensity can be mapped to the curve, and the output data are in the text format. ga, gr, $\mathrm{nr}$, and na in the file names, respectively, represent the axial sealing position width, the radial sealing position height, the radial teeth number, and the axial teeth number. In the first column, $s$ is the leakage path length, and in the second column, $A$ is the magnetic induction intensity at the current point corresponding to $s$. The following are the steps of data processing: the first step is to find out the peaks and troughs of the curve and calculate the difference between each peak and trough. In the second step, according to the model and the formula in this paper, the corresponding difference is calculated to get the total magnetic induction strength difference of the seal. The third step is to multiply 
the total magnetic induction difference and the saturation magnetization of the magnetic fluid to obtain the total pressure resistance of the seal. (Supplementary Materials)

\section{References}

[1] M. Bekovic, M. Trbusic, M. Trlep et al., "'Magnetic fluids' heating power exposed to a high-frequency rotating magnetic field," Advances in Materials Science and Engineering, vol. 2018, pp. 1-7, 2018.

[2] P. N. Kaloni and A. Mahajan, "Stability and uniqueness of ferrofluids," International Journal of Engineering Science, vol. 48, no. 11, pp. 1350-1356, 2010.

[3] M. Szczech and W. Horak, "Tightness testing of rotary ferromagnetic fluid seal working in water environment," Industrial Lubrication and Tribology, vol. 67, no. 5, pp. 455-459, 2015.

[4] H. Wang, D. Li, X. He, and Z. Li, "Performance of the ferrofluid seal with gas isolation device for sealing liquids," International Journal of Applied Electromagnetics and Mechanics, vol. 57, no. 1, pp. 107-122, 2018.

[5] Y. Mitamura and C. A. Durst, "Miniature magnetic fluid seal working in liquid environments," Journal of Magnetism and Magnetic Materials, vol. 431, pp. 285-288, 2017.

[6] D.-Y. Kim, H.-S. Bae, M.-K. Park et al., "A study of magnetic fluid seals for underwater robotic vehicles," International Journal of Applied Electromagnetics and Mechanics, vol. 33, no. 1-2, pp. 857-863, 2010.

[7] H. Urreta, G. Aguirre, P. Kuzhir, and L. N. Lopez de Lacalle, "Seals based on magnetic fluids for high precision spindles of machine tools," International Journal Of Precision Engineering And Manufacturing, vol. 19, no. 4, pp. 495-503, 2018.

[8] P. Zhang, B. Gu, J. Zhou, and L. Wei, "On hydrodynamic lubrication characteristics of ferrofluid film in a spiral groove mechanical seal," Industrial Lubrication and Tribology, vol. 70, no. 9, pp. 1783-1797, 2018.

[9] Z. Wang and D. Li, "Theoretical analysis and experimental study on loading process among stages of magnetic fluid seal," International Journal of Applied Electromagnetics and $\mathrm{Me}$ chanics, vol. 48, no. 1, pp. 101-110, 2015.

[10] S. Zhao, Q. Sheng, S. Lin, F. Zhang, and L. Jiao, "The model of seal mechanism for magnetic fluid and related experimental study," Mechanika, vol. 22, no. 4, pp. 260-264, 2016.

[11] M. Szczech and W. Horak, "Numerical simulation and experimental validation of the critical pressure value in ferromagnetic fluid seals," IEEE Transactions On Magnetics, vol. 53, no. 7, pp. 1-5, 2017.

[12] M. Szczech, "Experimental study on the pressure distribution mechanism among stages of the magnetic fluid seal," IEEE Transactions on Magnetics, vol. 54, no. 6, pp. 1-7, 2018.

[13] X. L. Yang and D. C. Li, "Experimental investigation of diverging stepped magnetic fluid seals with large sealing gap," International Journal of Applied Electromagnetics and Mechanics, vol. 50, no. 3, pp. 407-415, 2016.

[14] X. Yang, P. Sun, F. Chen, F. Hao, D. Li, and P. J. Thomas, "Numerical and experimental studies of a novel converging stepped ferrofluid seal," IEEE Transactions on Magnetics, vol. 55, no. 3, 2019.

[15] X. Yang, F. Hao, W. Xu et al., "Leakage path study of a diverging stepped magnetic fluid seal with large gap," International Journal of Applied Electromagnetics and Mechanics, vol. 60, no. 3, pp. 327-335, 2019. 